\title{
Agamenon R. E. Oliveira, A History of the Work Concept: From Physics to Economics (New York and London: Springer, 2014)
}

\author{
Babak Amini \\ York University, Toronto, Canada \\ Email: b.amini86@gmail.com
}

Received 5 August 2015; accepted 28 August 2015; published 1 September 2015

Copyright (C) 2015 by author and Scientific Research Publishing Inc. This work is licensed under the Creative Commons Attribution International License (CC BY). http://creativecommons.org/licenses/by/4.0/

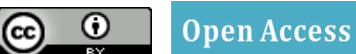

\section{Book Review}

This book seeks to trace the historical evolution that led to the emergence of the concept of work. Oliveira's clearly Marxist stance sets the starting point of his analysis from a definition of labour which he defines broadly as "physical action" (219) that connects human beings with nature. After reviewing the ways by which labour, as energetic actuation, has been conceptually understood and socially organized in various historical periods, he argues that the specific form of appropriation of surplus value and labour organization under industrial capitalism facilitated the emergence of machinism (xiii). It sees the concept of work, in its development in mechanics and political economy, as a bridging factor between physics and economics (200, 217), as the latter came to characterize the use-value and the later exchange-value of the capitalist form of commodity production (xvii). The book is almost entirely dedicated to understanding the historical evolution of the concept of work in physics, locating the genesis of the concept of work in the history of rational mechanics (stretched across several centuries in different countries by thinkers such as Aristotle, Galileo, Newton, Leibniz, and Lagrange) and detecting its eventual conceptualization in machine theory (developed in the $18^{\text {th }}$ century primarily in France and England by scientists such as Bernoulli, Borda, Coulomb, Carnot, and Coriolis).

Chapter 1, Theoretical Framework, is the most puzzling part of the book. Although clear on its own, the relation of some parts of this chapter, which includes discussion on Historical and Dialectical Materialism, Genetic Epistemology, Ecological Economics, and Historiography, to the rest of the book remains vague. Without author's clarification on how these theoretical frameworks help with the historical inquiry, inferring why they are mentioned seems generally difficult, confusing, and at times, arbitrary and unnecessary. Chapter 2 of the book briefly covers the historical development of some basic concepts such as space, time, force, and mass that facilitated the (non-deterministic) emergence of concept of work, and it demonstrates how mathematics came to be used in construction of physical concepts in general. Chapter 3 gives an historical account of the various directions and contexts in which the concept of work was conceived, including the principle of virtual work (whose genesis is the notions of vis viva [living force] and Principle of Least Action), and the study of machines to find an invariant quantity when the system is in motion (whose genesis is the concept of energy and dynamics). These theoretical elaborations found their full realization and coherent formulation later on in the general theory of machines. Chapter 4 reviews the long history of the development of rational mechanics from its association 
with astronomy to machine manufacturing, from ancient times to the $19^{\text {th }}$ century.

Chapters 5 and 6 lay out the development of the fundamental principles of rational mechanics when they were applied to the study of machines primarily in works of Lazare Carnot. The scientific achievements of Carnot is presented in juxtaposition with his political careeras a committed and engaged republican in the context of the French Revolution. On the basis of a thorough exploration of Carnot's scientific memoirs of 1779 and 1789 as well as his masterpiece the Fundamental Principles of Equilibrium and Motion, Oliveira explains how Carnot came to develop the general theory of machines. Carnot also discussed the question of efficiency a machine, although it was developed widely by other applied scientist such as Navier, Coriolis, and Poncelet (151f). The general theory of machines required a general understanding of machines regardless of what particular tasks for which they are utilized. There was already an economic motivation behind the definition of machine work as it was characterized by "the capacity of a machine to elevate a given weight to a certain height" (174). Hence, machine work was seen as general potentiality to do certain amount of work that can be used in a wide variety of tasks.

Chapter 7 delves into the discussion of how the interrelation between physics and economics finds its manifestation in the concept of work. The term work was adapted by the French scientific community after it was coined by Coriolis in 1829. One of the first scientists who investigated mechanical friction systematically, Coloumb was responsible for introduction of economic studies into machines. To do this, he interpreted human work mechanically (i.e. seeing the human body as a machine capable of doing certain amount of work) which then allowed him to understand machine work economically (191-2). Navier sought to find an equivalent quantity to make two types of machine works commensurate. He introduced the notion of mechanical currency anchored not on market value of the commodities produced by the capacity to produce commodities. It is interesting to note that, although the formation of concept of work incorporated economic considerations, it was repeatedly concluded to be a quantity independent of time (207) since, as Oliveira mentions earlier in the book, science of machines primarily facilitated the particular formation of the use-value aspect of capitalist commodity production, and as such, it does not need to be temporally grounded.

This book is not only a valuable contribution to the history of applied science and mechanical engineering, but also a good attempt to combine Kuhnian model of science historiography (i.e. non-cumulative and evolutionary account of scientific progress) with Marxist analysis. 